\title{
SERVICE AREAS OF LOCAL URBAN GREEN SPACES: AN EXPLORATIVE APPROACH IN ARROIOS, LISBON
}

\author{
Rossano Figueiredo ${ }^{\mathrm{a}, *}$, Alexandre B. Gonçalves ${ }^{\mathrm{a}, \mathrm{b}}$, Isabel Loupa Ramos ${ }^{\mathrm{a}, \mathrm{c}}$ \\ ${ }^{a}$ Instituto Superior Técnico, University of Lisbon, Lisbon, Portugal - rossanomanuel20@gmail.com \\ ${ }^{\mathrm{b}}$ CERIS-ICIST, DECivil/IST, University of Lisbon, Lisbon, Portugal - alexandre.goncalves@ tecnico.ulisboa.pt \\ ${ }^{c}$ CERIS-CESUR, DECivil/IST, University of Lisbon, Lisbon, Portugal - isabel.ramos@ tecnico.ulisboa.pt
}

KEY WORDS: Service Area, Local Urban Green Spaces, Attractiveness, Accessibility, Walkability, GIS

\begin{abstract}
:
The identification of service areas of urban green spaces and areas with lack of these is increasingly necessary within city planning and management, as it translates into important indicators for the assessment of quality of life. In this setting, it is important to evaluate the attractiveness and accessibility dynamics through a set of attributes, taking into account the local reality of the territory under study. This work presents an operational methodology associated with these dynamics in local urban green spaces, assisting in the planning and management of this type of facilities. The methodology is supported firstly on questionnaire surveys and then on network analysis, processing spatial data in a Geographic Information Systems (GIS) environment. In the case study, two local green spaces in Lisbon were selected, on a local perspective explorative approach. Through field data, it was possible to identify service areas for both spaces, and compare the results with references in the literature. It was also possible to recognise areas with lack of these spaces. The difficulty to evaluate the dynamics of real individuals in their choices of urban green spaces and the respective route is a major challenge to the application of the methodology. In this sense it becomes imperative to develop different instruments and adapt them to other types of urban green spaces.
\end{abstract}

\section{INTRODUCTION}

The evaluation of accessible and attractive green spaces is an integral part of urban quality of life (Herzele \& Wiedemann, 2003), as the quantity, distribution and accessibility can be major contributions to the social and ecological functioning in urban environments (Barbosa et al., 2007). As such, it is imperative to evaluate the respective attractiveness and accessibility dynamics to increase the use, improve access and enhance their role and overall benefits in the urban environment. The importance of having green spaces nearby the residential areas and the positive association between close distance and increased use are mentioned in various health policies and urban planning guidelines, becoming a contemporary issue (Schipperijn et al., 2010), a theme with significant impact in governance priorities.

\section{PUBLIC GREEN SPACES}

\subsection{Historical background}

The concept of public space has always existed, specially in Ancient Greece, where the development of democracy led to a more substantial popular participation in community affairs (Goitia, 2008). According to Telles (p. 55, 1997) "the public urban green space, as it is understood today, appears primarily from the eighteenth century". References of these are the Passeio Público in Lisbon and the Louvre-Étoile axis in Paris, built for the public leisure use. At the same time the first urban parks appeared, offering to the community large spaces in the context of the emergence of suburban middle classes and the growth of industrialized cities. With the Industrial Revolution the need to correct poor health conditions has risen, triggering the idea of improving the environment by integrating green spaces in the city. On the other hand, Magalhães (1992) believes that the urban green space concept emerged after the post-industrial era, like a space that intents to create the presence of nature and rural components in the urban environment. In this perspective, these spaces, beyond their ecologic and health component, were already seen as a means of social integration. Later, Frederick Olmsted (the author of Central Park, New York) proposed the primitive concept of "green lung" and developed it through the idea of a continuous system of parks as a way to structure and improve the urban fabric while controlling urban growth. On the same line is the separation of pedestrian and traffic spaces. This new urban models reflect on the mid-19th century the Romantic Movement which spreads along Europe, including Lisbon, by creating park systems on the consolidated or expanding urban fabric.

In the early 20th century, the previous concepts have been developed, enabling the rise of the "continuum natural" theory (Magalhães, 1992), towards the green structure transformation into a more continuous network, not only in the city centre but also in its surroundings, holding a circulation urban function (Telles, 1997). With this more integrated vision, not only new spaces were built but also requalification efforts of previous green areas were conducted. Corridors along main traffic routes had been afforested to connect the main green sites, from small gardens to forest parks located outside the city. The emergence of rationalist theories presented on the Athens Charter (1943) has fundamentally changed the concept of urban green space (Telles, 1997). This document, which defines the modern and functional urbanism paradigm, considered the green spaces as free large areas that should be released by the construction of

\footnotetext{
* Corresponding author
} 
high buildings, highlighting their role in the urban quality of life.

Over time, the concepts associated with these spaces have expanded: the physical and psychological contributions of these spaces for human health have been discussed, and there is an increased attention and evidence on their positive relation (e.g. Vries et al, 2003; Mitchell \& Popham, 2007, Takano et al, 2002 in Tzoulas et al., 2007; Maas et al, 2009). Recent studies focus on issues of usefulness, attractiveness and accessibility, where the theme of "walkability", the compatibility of the urban environment with pedestrian habits as defined by Abley and Turner (2011), has increasingly being present, due to the contemporary need to search for sustainability and healthy life (Cambra, 2012).

\subsection{The scale of local urban green spaces}

There is not an universal concept that can be conferred to local urban green spaces, at a local scale, but from the literature it is possible to have some knowledge of their characteristics. According to Gupta et al. (p. 326, 2012), the neighbourhood range is synonymous with proximity and can be defined as an area of homogeneous characteristics, the scale being considered for the application of green strategies. This type of small green spaces is generally located in consolidated urban centres, which may have a strong connection with the local lifestyle, having a social action component (Herzele \& Wiedemann, 2003). There is a long-lasting tradition in research that explores the relationship between the characteristics of proximity and the individual well-being (Macintyre \& Ellaway, 2000 in Tzoulas et al., 2007): it has been proved that the level of proximity and the availability of green spaces affect the quality of the environment, helping in restoring stress, increasing the feeling of safety (Maas et al., 2009), the social interaction and the real estate value (Jim \& Chen, 2012 in Gupta et al., 2012) and also providing a recreational space for the physical and mental development of children (Jacobs, 1961 in Gupta et al., 2012).

\begin{tabular}{|l|l|}
\hline $\begin{array}{l}\text { Accessibility distance } \\
\text { and time }\end{array}$ & Author(s) \\
\hline $400 \mathrm{~m}-5 \mathrm{~min}$ & $\begin{array}{l}\text { Herzele \& Wiedemann, 2003; } \\
\text { Boone et al., 2009; Wendel et } \\
\text { al., 2012 } \\
\text { Matthews, 1987; Hillman et al., } \\
\text { 1990; Magalhães, 1992 } \\
\text { Coles \& Bussey, 2000; Giles- } \\
\text { Corti et al., 2005; Grahn \& } \\
\text { Stigsdotter, 2003; Nielsen \& } \\
\text { Hansen, 2007 } \\
\text { EEA, 2007; Stanners \& } \\
\text { Bourdeau, 1995 } \\
\text { English Nature, 2005; Harrison } \\
\text { et al., 1995; Barker, 1997; } \\
\text { Handley et al., 2003; Wray et al., } \\
\text { 2005 }\end{array}$ \\
\hline
\end{tabular}

Table 1. Maximum accessibility distance and time standards of local green spaces found in the literature

There are already standardized parameters for the maximum residence to green space distances and for the minimum dimensions of the various types of urban green spaces (MIRAS, 2000). Table 1 summarizes values collected from the literature for the accessibility time and distance to this type of spaces. These values are maximum standards (stated as acceptable), denoting how much is perceived as reasonable.
Some of these entries were recommended by European and National government institutions. In general, it is noticeable that the maximum acceptable distance for accessing urban green spaces is 400 meters, which in general corresponds to a ca. 5 minutes walking journey. These values are merely general recommendations and must be contextualized with local characteristics and conditions.

On the Portuguese research references, this type of urban green spaces appears as being close to residential areas (GEPAT, 1990). With this reference document, although not updated, comes the need to establish and adopt minimum standards for the planning and design of these spaces, including minimum areas and maximum distance (Magalhães, 1992). These spaces are located between 100 and 400 meters from households, covering all the inhabitants in the neighbourhood. The main difference between these spaces and larger urban parks, beyond the small dimension, is its daily and casual use.

\section{ATTRACTIVENESS AND ACCESSIBILITY OF URBAN GREEN SPACES}

\subsection{Concept}

The attractiveness concept is associated with specific characteristics of several urban green space categories, which differ from the context of the surrounding area, defining its use. Giles-Corti et al. (2005 in Wendel et al., 2012) consider that there are "a set of factors that influence the use of public green spaces, including: the quality and quantity of spaces, the sociodemographic characteristics of potential users, access to facilities, ability to meet the needs of users, maintenance and the perception of safety". In this sense, the choices of the space do not fall only on associated physical factors, but may also be influenced by individual preferences (Koohsari et al., 2013), even though it is expected to visit the spaces that are nearby the residence or work places, or those which have higher levels of attractiveness associated with quality. Therefore, a set of formal and informal, physical and psychological, objective and subjective factors weight in the choice of a green space. The attractiveness is associated with accessibility, as it may be a determinant attribute for the use of certain urban areas (Corti et al., 1996), respectively related to physical and/or psychological barriers found by individuals on their daily journeys.

Accessibility can be defined as "the ability of the environment to provide all people an equal opportunity to use a direct, immediate, permanent and autonomous way as much as possible" (p.21, CML, 2013). It is an important component of any urban public space since proximity to these areas impacts positively on physical, mental and social aspects, ranging from the quality of life (Coombes et al., 2010 in Koohsari et al., 2013) to the improvement of air quality and community cohesion (Davies et al., 2011 in Koohsari et al., 2013).

Accessibility to green spaces can be evaluated through the service area analysis, providing a base measure for assessing the availability of green spaces to residents within a specified distance. In general, this intends to evaluate the distribution and potential gaps in the studied area (Boone et al., 2009 in Wendel et al., 2012). The accessibility conditions influence the use of such spaces, establishing the extent of use and the profile of its regular users, since an accessible green space may be used for a diverse group of individuals (including the elderly, children and individuals with mobility impairments). Indeed, in recent years, a growing body of evidence indicates that a range of perceived environments and objectively measured attributes (including access) are associated with patterns of pedestrian walk (Owen et al., 2004; Giles-Corti et al., 2005 in Sugiyama et al., 2013). On 
the other hand, Koohsari et al. (p. 92, 2013) indicates that "different aspects of public open spaces can influence the walk", getting the idea that not only the conditions of the area around a green space and its access influence the choice of journey and pedestrian behaviour, but also what is inherent to the space itself can be determined in the manner of how individuals get to their destinations.

\subsection{Attributes of attractiveness and accessibility}

To prepare the questionnaire surveys, identify the user dynamics in terms of attractiveness and accessibility and apply spatial analysis techniques, it was necessary to review the existing literature to support the choice of attributes associated with the two abovementioned concepts. The main issue is not to assess formally the green spaces under study or their quality, but to understand the key preferences or motivations related with use and access. While some attributes are objective and can be easily measured, for example time and distance quantifications, others are more informal, having a more empirical support, such as aesthetic perceptions. Given the content similarities, attributes were arranged into accessibility and attractiveness themes. Table 2 summarizes a set of attributes and the respective references.

\begin{tabular}{|c|c|}
\hline Attribute & Author(s) \\
\hline $\begin{array}{l}\text { distance and } \\
\text { proximity to space }\end{array}$ & $\begin{array}{l}\text { Coles \& Bussey, 2000; Roovers et al., } \\
\text { 2002; Herzele \& Wiedemann, 2003; } \\
\text { Grahn \& Stigsdotter, 2003; Jensen \& } \\
\text { Koch, 2004; Humpel et al., 2004; } \\
\text { Owen et al., 2004; Giles-Corti et al., } \\
\text { 2005; Nielsen \& Hansen, 2007; Bjork } \\
\text { et al., 2008; Schipperijn et al., 2010; } \\
\text { Choumert, 2010; Koohsari et al, } 2013\end{array}$ \\
\hline $\begin{array}{l}\text { easiness of getting } \\
\text { to space and } \\
\text { physical effort }\end{array}$ & $\begin{array}{l}\text { Handy, 1996; Sisiopiku \& Akin, } \\
\text { 2003; Brown et al., } 2007\end{array}$ \\
\hline $\begin{array}{l}\text { aesthetic and } \\
\text { space's } \\
\text { environment }\end{array}$ & $\begin{array}{l}\text { Deconinck, 1982; Harrison and } \\
\text { Burgess, 1988; Grahn, 1991; } \\
\text { Coeterier, 2000; Herzele \& } \\
\text { Wiedemann, 2003 }\end{array}$ \\
\hline $\begin{array}{l}\text { friends, family and } \\
\text { neighbourhood } \\
\text { individuals }\end{array}$ & Bertera, 2003; Schipperijn et al, 2010 \\
\hline supporting facilities & $\begin{array}{l}\text { Burgess et al., 1988; Berggren- } \\
\text { Barring \& Grahn, 1995; Holm, 1998; } \\
\text { Coles \& Bussey, 2000; Herzele \& } \\
\text { Wiedemann, 2003; Giles-Corti et al., } \\
\text { 2005; Kaczynski et al., 2009; Reyes } \\
\text { \& Figueroa, 2010; Wendel et al., } \\
\text { 2012; Maruthaveeran \& Bosch, } 2014\end{array}$ \\
\hline $\begin{array}{l}\text { cleanliness, } \\
\text { maintenance and } \\
\text { treatment }\end{array}$ & $\begin{array}{l}\text { Shaffer \& Anderson, 1985; Giles- } \\
\text { Corti et al., 2012; Maruthaveeran \& } \\
\text { Bosch, } 2014\end{array}$ \\
\hline personal meaning & Berggren-Barring \& Grahn, 1990 \\
\hline exclusivity of space & Herzele \& Wiedemann, 2003 \\
\hline safety & $\begin{array}{l}\text { Hovell et al.,1989; Madge, 1997; } \\
\text { Wendel et al., 2012; Jansson et al., } \\
\text { 2013; Maruthaveeran \& Bosch, } 2014\end{array}$ \\
\hline slope & Penn, 2003; Miller \& Lida, 2005 \\
\hline time & $\begin{array}{l}\text { Deconinck, 1982; Grahn, 1994; } \\
\text { Bussey, 1996; Holm, 1998; Owen et } \\
\text { al., } 2004\end{array}$ \\
\hline $\begin{array}{l}\text { pedestrian } \\
\text { crossings }\end{array}$ & Owen et al., 2004; CML, 2013 \\
\hline
\end{tabular}

\begin{tabular}{|c|c|}
\hline abusive parking & CML, 2013 \\
\hline $\begin{array}{l}\text { conditions and } \\
\text { width of pedestrian } \\
\text { crossings }\end{array}$ & CML, 2013 \\
\hline obstacles & CML, 2013 \\
\hline $\begin{array}{l}\text { services, trade and } \\
\text { public facilities }\end{array}$ & Owen et al., 2004 \\
\hline $\begin{array}{l}\text { traffic, pollution } \\
\text { and noise }\end{array}$ & $\begin{array}{l}\text { Giles-Corti \& Donovan, 2002; Owen } \\
\text { et al., 2004; Sugiyama \& Thompson, } \\
\text { 2008; Koohsari et al., } 2013\end{array}$ \\
\hline tress and shadow & $\begin{array}{l}\text { Sugiyama \& Thompson, 2003; Giles- } \\
\text { Corti \& Donovan, 2003; Lamas, } 2011\end{array}$ \\
\hline street furniture & Owen et al., 2004 \\
\hline $\begin{array}{l}\text { environment / } \\
\text { aesthetic and } \\
\text { associated feelings }\end{array}$ & $\begin{array}{l}\text { Sallis \& Owen, 1999; ABS, 2000; } \\
\text { Bargh \& Ferguson, 2000; Ball et al., } \\
\text { 2001; Bauman et al., 2002; Craig et } \\
\text { al., 2002; Giles-Corti \& Donovan, } \\
\text { 2002; Trost et al., 2002; Owen et al., } \\
\text { 2004; Humpel et al., 2004; Gobster, } \\
\text { 2005; Sugiyama \& Thompson, 2008; } \\
\text { Sugiyama et al., } 2013\end{array}$ \\
\hline walking pleasure & $\begin{array}{l}\text { Giles-Corti \& Donovan, 2002; Owen } \\
\text { et al., 2004; Humpel et al., } 2004\end{array}$ \\
\hline
\end{tabular}

Table 1. A summary of attractiveness and accessibility attributes for urban green spaces found in the literature

\subsection{Service areas}

From the spatial analysis of service areas it is possible to understand the influence that a given point has to condition the users behaviour (or journey), taking into account the characteristics of the street network. Basically, the service area of an urban green space covers the territory where its potential users live, extending to the farthest user patronizing such space. These assumptions are different from those applying to other types of urban green spaces. The shape of service areas is also dependent on the spatial representation of distances, either in direct Euclidean distance, considering isotropic territory, or measuring accumulated distances along a structured network. The concept can also be applied to any facility or service.

\section{METHODOLOGY}

The present methodology was divided in two distinct stages: firstly, a questionnaire survey, which was applied on the two local green spaces under study to find out the motivations and main factors that influence the choice for a green space by the respondents. Following the key concepts of this work, the survey was structured around the attractiveness and accessibility concerns. Attractiveness is important in determining the frequency of visit, trying to understand the reasons and motivations for visiting a particular green space. On that sense, a relevance scale was set (important, not important and unrelated) with the attributes already referenced. Also, the inquirees were asked to identify their journey origin locations (home or work) to enable the future intersection with the service area in the spatial analysis process.

The second stage consisted in the production of service areas, using a geographic information system (GIS) desktop software, namely ArcGIS 10.1 and the Network Analyst extension. On this process, a time cost attribute (in seconds) was used to output service areas, where the supporting network included attributes such as slope and length of each street segment. The cost of passing through each segment was calculated in either direction using speed and time values from the formula proposed by Tobler (1993) (Tobler's hiking function). This 
exponential function determines the walking speed, taking into account the slope angle, the distance and the effect that the slope direction has on speed. It is important to emphasize that this function does not consider the age or physical condition of each individual. Also, the cost network created in GIS did not consider barriers or physical obstacles besides the slope, such as stairs, sidewalk conditions, etc. After the network construction several service areas were defined according to time intervals (2 minutes) up to 16 minute journeys, as this last value was the highest journey duration to access the green spaces from survey data. Moreover, this value is also in accordance to general recommendations found in the literature.

\section{CASE STUDY}

\subsection{Description}

The Arroios district, one of the most densely populated and urbanized areas of Lisbon, was selected to be the case study of the present work; the reasons to select it were its location within the consolidated urban centre, the existence of local urban green spaces and a low value of green space area per inhabitant. Two green spaces were selected based on their characteristics and territorial impact: Jardim Constantino and Campo Mártires da Pátria.

\subsection{Service area delimitation}

From survey data, it was clear that "proximity" to the space, "ease of access", "supporting facilities" and "safety" were the most important attractiveness attributes $(98.6 \%$ of total respondents), while "personal reasons" and "exclusivity of space" were attributes mostly considered as unrelated (91.9\%). The other major motivations for using urban green spaces were "leaving home" or "incidentalness" (37.8\%), "spending free time" (33.8\%) and "walking or walking the dog" (32.4\%). Almost half (41.6\%) of the inquirees use exclusively the urban green space where they were surveyed, which is not a surprise since the majority was elderly population who lives nearby and most have mobility impairments. The main transportation mode was "walking" $(98.7 \%)$ and the average time spent was in the "6 to 10 minutes" range (54.5\%). It was observed that in Jardim Constantino the "0 to 5 minutes" journey time gains more expression probably because of residential surroundings and the fact of the nearby neighbourhood is located within that travel time. The majority $(89.6 \%)$ follows the same route everytime, as it is the "most direct and fastest route" (87.0\%) according to the individual perception. Regarding to the accessibility attributes, the most valued were "distance" (100.0\%), "safety" (100.0\%), "[existence of] trees and shadows" (100.0\%), followed by "duration" (98.7\%) and "slope" (94.8\%). The most unappreciated attributes for choosing the access route were "walking pleasure" (9.1\%), "environment or aesthetics, and associated feelings" (10.4\%), "street furniture" (46.8\%) and "friends or family's home or work" (49.4\%).

The majority of Jardim Constantino respondents origins are within the 2 to 4 minutes $(36.84 \%)$ and 4 to 6 minutes (31.58\%) ranges. On the other hand, in Campo Mártires da Pátria the preponderance is in the 6 to 8 minutes range $(35.9 \%)$. In this last space the lowest percentage of respondents is in the 2 to 4 minutes range $(2.56 \%)$. These observations (Figures 1 and 2) suggest that the Campo Mártires da Pátria service area (12 minutes) is larger than that of Jardim Constantino ( 8 minutes). This assumption can be explained by some characteristics of this space: its proximity to the city center, the concentration of large public facilities (faculties and other institutional buildings) in the adjacency of the area, leaving only a few residential buildings, and its touristical location, all combine to attract mostly people from outer locations. On the other hand, Jardim Constantino seems to attract mostly local residents for daily use.

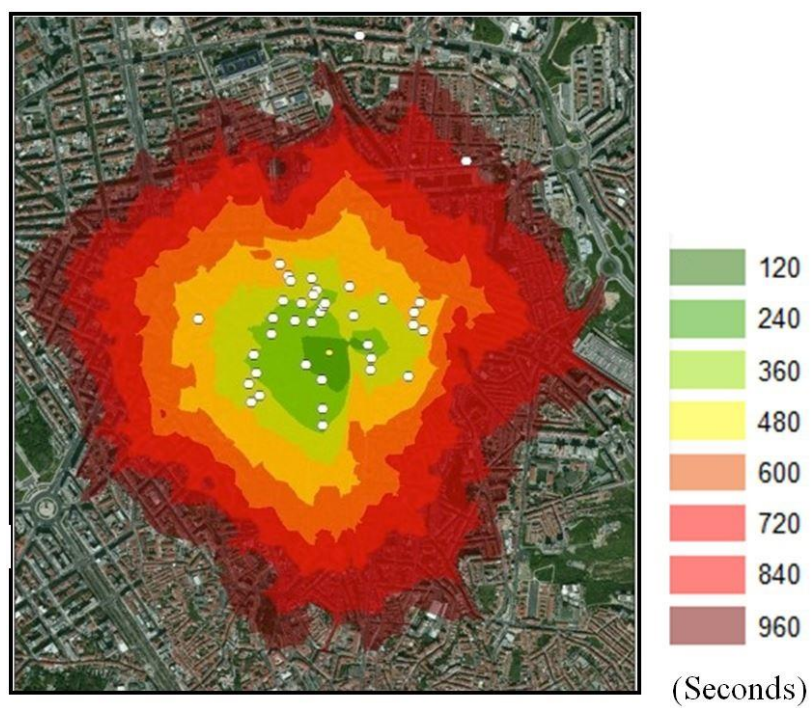

Figure 1. Jardim Constantino service area overlapped with origins of inquired users
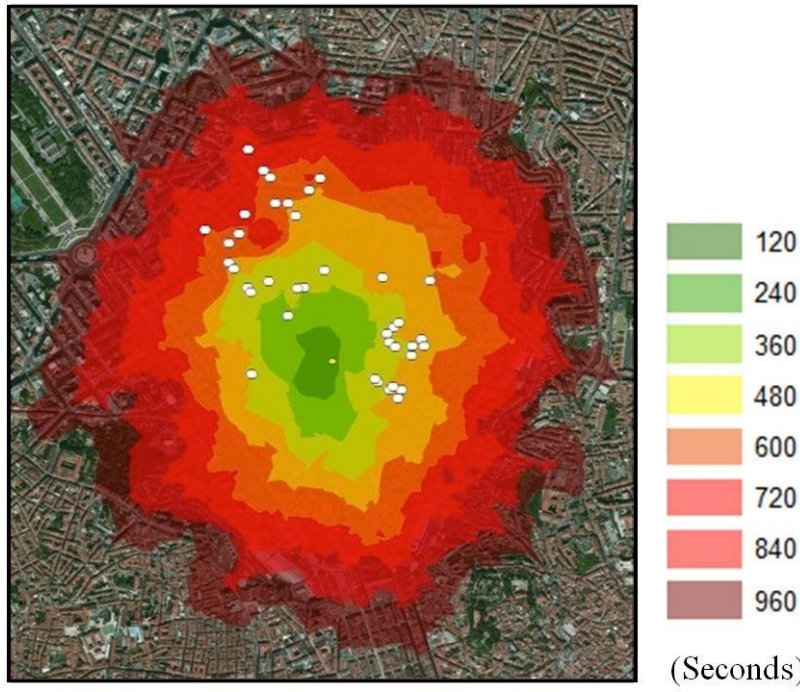

(Seconds)

Figure 2. Campo Mártires da Pátria service area overlapped with origins of inquired users

This kind of information it is different from the surveys time information because of the limited and reducer criteria used to create the cost network, which was not considered the age or physical performance of each individual, just like was said earlier. The function used is more targeted to active adult individuals, instead of the elderly population that translates the majority of ours respondents and will naturally have some height on route's time. It was also possible to see that the majority of respondents are conforming to the general recommendations (10 minutes). This value appears from the recommended values by most institutions and researches (5-15 minutes) and the surveys' results (6-10 minutes). 


\subsection{Identification of areas with lack of local green spaces}

After determining the service areas according to the described methodology, it was possible to extend the analysis to identify areas in need of urban green spaces and in an ensuing exploratory approach for the detection of potential sites for such facilities. This was done in the contiguous parishes of Penha de França and São Vicente. The process and associated concepts were the same for the delimitation of service areas, but with an inverse approach: firstly, it is necessary to identify the existing local urban green spaces and the free areas vacant areas, i.e. with no construction but having public access and adequate size to be considered as potential facilities; then, a 10 minutes reference value was used to delimitate the service areas of all the existing spaces. Therefore, it was possible to inspect the vacant areas in terms of their potential individual coverage using the same temporal reference value for access, and calculate the area with lack of local green spaces. Results indicate that $53 \%$ of the area of Penha de França and $47 \%$ of São Vicente are lacking local green spaces. This figures do not mean that the lack of spaces is so relevant, since Penha de França, for instance, has a significant area with no residential function. Figure 3 displays the potential vacant spaces, particularly the four with the largest potential values (area currently uncovered).

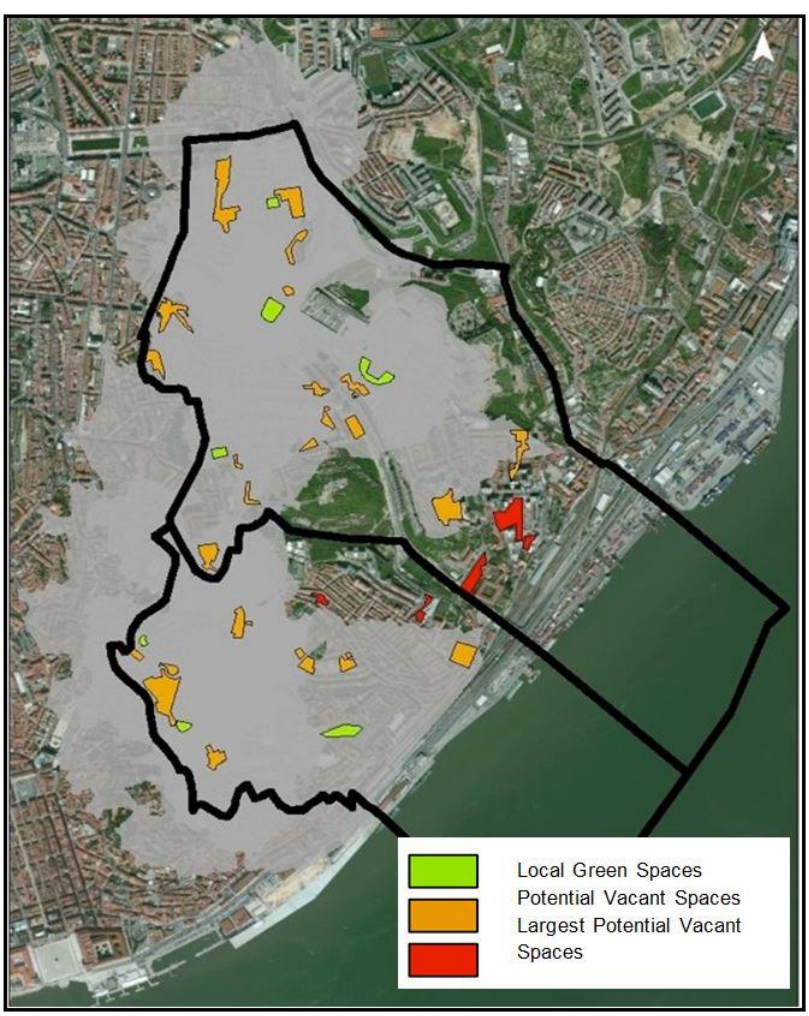

Figure 3. Areas covered by local green spaces in Penha de França and São Vicente, Lisbon, and identification of vacant spaces

\section{CONCLUSIONS}

Results of the conducted survey expressed that safety, proximity (distance and time), ease of travel (slope), and presence of trees and shadow on the path to local green spaces were the factors with the greatest weight in the choice and route to destination as stated by the inquiries. It was found that the dynamics of accessibility override the characteristics of attractiveness, as users have a practical perspective concerning the access and use of these spaces. The users emphasize, among all the inquired criteria, the proximity to the destination and follow the most direct route. Physical attributes related with impedance, i.e., with direct practical implications on the individual effort, had a higher significance in comparison with the quality of space, the urban environment and unique characteristics of the destination. It can also be observed that the two analysed spaces have distinct service areas and both respect the usual temporal general recommendations on accessibility.Since the proximity and easiness of the route are essential factors to access these spaces, these findings may be considered in future research and in intervention proposals related with the development of networks of local urban green spaces.

The methodology is an alternative approach to the standard indicator of capitation of green spaces, validating the need for intervention on territories which are not covered by service areas. The explored extension of the methodology allows to easily identify areas with lack of urban green spaces and assess each potential vacant space in terms of service area coverage. As most individuals value the distance to local green spaces and a direct and quick access, the methodology supports the development of a dense and continuous network of such facilities.

\section{REFERENCES}

Abley, S., Turner, S., 2011, Predicting Walkability: Technical Report, New Zealand Transport Agency.

Barbosa, O., Tratalos, J., Armsworth, P. Davies, R., Fuller, R., Johnson, P., Gaston, K., 2007, Who benefits from access to green space? A case study from Sheffield, UK. Landscape and Urban Planning, 83, pp. 187-195.

Cambra, P., 2012, Pedestrian accessibility and atractiveness indicators for walkability assessment. MSc thesis on Urbanism and Territorial Planning, Instituto Superior Técnico, Technical University of Lisbon, Portugal.

Câmara Municipal de Lisboa, 2013, Plano de Acessibilidade Pedonal de Lisboa, Lisboa: Volume 2 Área Operacional Via Pública. Núcleo de Acessibilidade Pedonal de Lisboa, CML.

Coles, R., Bussey, S., 2000. Urban forest landscapes in the UK-progressing the social agenda. Landscape Urban Planning, 52, pp. 181-188.

Corti, B., Donovan, R. J., Holman, C. D. J, 1996, Factors influencing the use of physical activity facilities: results from qualitative research. Journal of Health Promotion, 6, pp. 16-21.

GEPAT, 1990, Normas para a Programação de Equipamentos Colectivos, Vol. IV - Espaços Verdes, DSOT, Lisboa.

Goitia, Fernando. C., 2008. Breve História do Urbanismo. Editorial Presença, 7th ed., Lisboa.

Grahn, P., Stigsdotter, U., 2003. Landscape planning and stress. Urban Forestry \& Urban Greening, 2, pp. 1-18. 
Gupta, K., Kumar, P., Pathan, S.K., Sharma, K.P., 2012, Urban Neighborhood Green Index - A measure of green spaces in urban areas, Landscape and Urban Planning, 105, pp. 325-335.

Herzele, A., Wiedemann, T., 2003, A monitoring tool for provision of accessible and attractive urban green spaces, Landscape and Urban Planning, 63, pp. 109-126.

Humpel, N., Owen, N., Leslie, E., 2002, Environmental factors associated with adults' participation in physical activity: A review. American Journal of Preventive Medicine, 22, pp. 188199.

Jansson, M., Fors, H., Lindgren, T., Wistrom, B., 2013, Perceived personal safety in relation to urban woodland vegetation - A review, Urban Forestry \& Urban Greening, 12, pp. 127-133.

Jensen, F.S., Koch, N.E. 2004. Twenty-five years of forest recreation research in Denmark and its influence on forest policy. Scandinavian Journal of Forest Research, 19, pp. 93102.

Koohsari, M., Kaczynski, A., Gilles-Corti, B., Karakiewicz, J., 2013, Effects of access to public open spaces on walking: Is proximity enough?, Landscape and Urban Planning, 117, pp. 92-99.

Lamas, J., 2011, Morfologia Urbana e Desenho da Cidade, Fundação Calouste Gulbenkian, $6^{a}$ Edição, Lisboa.

Maas, J., van Dillen, S.M., Verheij, R.A., Groenewegen, P.P. 2009, Social contacts as a possible mechanism behind the relation between green space and health, Health \& Place, 15, pp. 586-595.

Magalhães, M. R., 1992, Espaços Verdes Urbanos, MPAT DGOT, $n^{\circ} 25$, Lisboa.

Maruthaveeran, S., Bosch, C.C.K, 2014a, A socio- ecological exploration of fear of crime in urban green spaces - A systematic review, Urban Forestry \& Urban Greening, 13, pp.1-18.

Owen N., Humpel N., Leslie E., Bauman A. Sallis J. F., 2004, Understanding Environmental Influences on Walking: Review and Research Agenda, American Journal of Preventive Medicine, 27, pp. 67-76.

Roovers, P., Hermy, M. Gulinck, H., 2002. Visitor profile, perceptions and expectations in forest from a gradient of increasing urbanisation in central Belgium. Landscape and Urban Planning, 59, pp. 129-145.

Schipperijn, J., Ekholm, O., Stigsdotter, U., Toftager, M., Bentsen, P., Kamper-Jorgensen, F., Randrup, T., 2010, Factors influencing the use of green space: Results from Danish national representative survey, Landscape and Urban Planning, 95, pp. 130-137.

Sugiyama, T., Giles-Corti, B., Summers, J., Dutoit, L., Leslie, E., Owen, N., 2013a, Initiating and maintaining recreational walking: A longitudinal study on the influence of neighborhood green space, Preventive Medicine, 57, pp. 178-182.

Telles, Gonçalo R., 1997, O Plano Verde de Lisboa: componente do Plano Director Municipal de Lisboa, Edições Colibri, Lisboa.
Tobler, W., 1993. Three presentations on geographical analysis and modeling: Non-isotropic geographic modeling speculations on the geometry of geography global spatial analysis. Technical report 93-1, National Center for Geographic Information and Analysis, Santa Barbara, California.

Tzoulas, K., Korpela, K., Venn, S., Vesa, Y., Kazmierczak, A., Niemela, J., James, P., 2007, Promoting ecosystem and human health in urban area using Green Infrastructure: A literature review, Landscape and Urban Planning, 81, pp. 167-178.

Wendel, H., Zarger, R., Mihelcic, J., 2012, Accessibility and usability: Green space preferences, perceptions, and barriers in a rapidly urbanizing city in Latin America, Landscape and Urban Planning, 107, pp. 272-282. 